\title{
Perancangan Dan Implementasi DC-DC Bidirectional Converter Dengan Sumber Energi Listrik Dari Panel Surya Dan Baterai Untuk Pemenuhan Kebutuhan Daya Listrik Beban
}

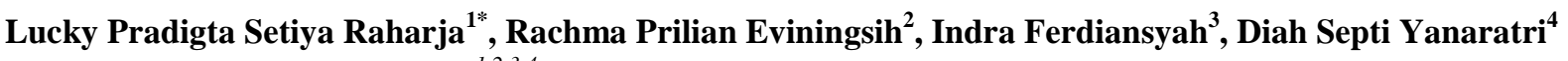 \\ ${ }^{1,2,3,4}$ Politeknik Elektronika Negeri Surabaya \\ *lucky@pens.ac.id
}

\begin{abstract}
Renewable energy continues to grow as electrical energy needs increase. One of the renewable energy technologies is the Solar Power Plant. The development of Solar Power Plant is supported by the Power Electronic Converter which is used to regulate electrical energy. One of the systems used is the load that gets electrical energy directly from Solar Power Plant. In this system there are conditions where PLTS is able to provide electrical power to the load and even allows generating more power, but there are also conditions where the Solar Power Plant is not able to provide electrical power to the load due to lack of sunlight. To regulate the electrical energy, a DC-DC converter is used by applying the bidirectional method. Bidirectional method on the DC-DC converter is 1 converter that has 2 functions of the Buck Mode and Boost Mode by using an automatic adjustment based on the voltage from the solar panel as a reference for determining the Mode on the converter. When the power generated from solar panels is 207.23 Watt it can be used to supply a load of 149.04 Watts and more power is used for charging batteries of 58.28 Watts through Buck Mode. When the power generated from the solar panel is 219.86 Watt, while the required power for a load of 232.53 Watt then to meet the load power is provided additional from the battery power of 12.97 Watt with boost mode works. By using this bidirectional method, the load power requirements can be met in conditions of excess power or when the power generated is less so that it requires additional power from battery power.
\end{abstract}

Keywords: Solar Power Plant, DC-DC Bidirectional, Solar Panel, Battery.

\begin{abstract}
Abstrak
Energi terbaharukan semakin berkembang untuk memenuhi kebutuhan energi listrik. Salah satu teknologi adalah Pembangkit Listrik Tenaga Surya (PLTS). Perkembangan PLTS didukung dengan Power Electronic Converter yang digunakan untuk pengolahan energi listrik. Salah satu sistem yang digunakan adalah beban mendapatkan sumber energi listrik langsung dari PLTS. Dengan system tersebut terdapat kondisi dimana PLTS mampu menyediakan daya listrik ke beban bahkan memungkinkan daya PLTS bisa lebih dan kondisi dimana PLTS tidak mampu menyediakan daya listrik ke beban dikarenakan kondisi dari sinar matahari yang kurang. Untuk mengatur sumber energy listrik tersebut menggunakan DC-DC converter yang menerapkan metode bidirectional. Metode bidirectional pada converter DC-DC merupakan 1 konverter yang bisa menjadi 2 fungsi Mode Buck dan Mode Boost dengan menggunakan pengaturan otomatis berdasarkan tegangan dari panel surya sebagai acuan untuk penentuan Mode pada converter. Pada saat daya yang dihasilkan dari panel surya sebesar 207.23Watt dapat digunakan memenuhi beban sebesar 149.04Watt dan daya lebih digunakan untuk pengisian baterai sebesar 58.28Watt melalui Mode Buck. Pada saat daya yang dihasilkan dari panel surya sebesar 219.86 Watt, sedangkan yang diperlukan daya untuk beban 232.53Watt maka untuk memenuhi daya beban disediakan tambahan dari daya baterai sebesar 12.97Watt dengan mode boost bekerja. Dengan menggunakan metode bidirectional ini kebutuhan daya beban dapat dipenuhi pada kondisi daya dari panel surya yang dihasilkan berlebih atau saat daya yang dihasilkan kurang dan dibantu dari daya baterai.
\end{abstract}

Kata kunci: PLTS, DC-DC Bidirectional, Panel Surya, Baterai. 


\section{Pendahuluan}

Kebutuhan energi listrik selalu meningkat dari tahun ke tahun. Untuk memenuhi kebutuhan energi listrik tersebut pemerintah selalu menjaga proses produksi listrik dari berbagai jenis pembangkit. Selain dari pembangkit listrik yang telah ada, energi listrik dapat diperoleh dari Renewable Energy. Di kawasan Indonesia sangat tepat untuk menerapakan Renewable Energy dengan memanfaatkan sinar matahari. Energi dari sinar matahari sangat mudah didapatkan di Indonesia karena merupakan daerah khatulistiwa yang kaya dengan sinar matahari [1], [2].

Pembangkit Listrik Tenaga Surya (PLTS) sangat tepat diterapkan di Indonesia. PLTS menggunakan panel surya untuk merubah sinar matahari menjadi energi listrik DC. Proses pemanfataan energy listrik dari PLTS perlu menggunakan konverter yang digunakan untuk pemenuhan kebutuhan listrik pada beban. Bebagai jenis Converter $D C-D C$ dapat digunakan dalam proses pemanfaatan energi listrik ke beban [1],[3],[4],[5]. Pada sistem yang menggunakan sumber dari PLTS dengan panel surya sebagai sumber energi listrik ke beban dapat menambahkan energi penyimpanan listrik untuk membantu menjaga kontinuitas sumber energi listrik ke beban. Energi penyimpanan listrik yang digunakan adalah bateray.

Kita ketahui bahwa besarnya tegangan beban harus dijaga sesuai spesifikasi tegangan beban. Sehingga untuk memenuhi besarnya tegangan pada beban maka dibutuhkan converter untuk menyesuaikan besarnya tegangan tersebut. Selain converter tersebut, kita juga menggunakan converter untuk proses pengisian tegangan listrik baterai dan converter dari baterai ke beban apabila sumber dari panel surya tidak mampu memberikan daya pada beban. Sehingga pada proses tersebut membutuhkan 3 konverter [4].

Pada penelitian ini mengusulkan converter DC-DC. Konverter DC-DC ini menggunakan metode bidirectional. Metode bidirectional pada converter DC-DC dapat difungsikan sebagai proses pengisian baterai dan sebagai proses penyedia sumber tegangan pada beban. Sehingga dengan adanya 2 fungsi pada 1 konverter tersebut dapat menyediakan sumber tegangan baik saat proses pengisian baterai maupun saat menyediakan sumber tegangan pada beban [3],[6].

Beban akan diberi sumber tegangan dari PLTS. Apabila daya yang disediakan oleh PLTS melebihi kebutuhan untuk beban, maka sisa daya dari PLTS akan digunakan untuk proses pengisian baterai. Apabila daya yang dihasilkan dari PLTS tidak cukup untuk beban, maka beban akan dialihkan sumbernya dari baterai. Sehingga kontinuitas sumber tegangan pada beban akan selalu terjaga sesuai spesifikasi PLTS dan bateray [2]. Pada desain ini menggunakan komponen switching dan komponen magnetic pada rangkaian konverter DC-DC. Untuk mendapatkan daya maksimal dari panel surya, system ini mengunakan Maximum Power Point Tracking (MPPT). Dengan menggunakan MPPT diharpkan dapat memaksimal daya dari panel surya sehingga dapat memenuhi dalam penyedian daya untuk beban dan pengisian baterai.

\section{Metoda Penelitian \\ 2.1. Konverter Buck}

Konverter Buck adalah salah satu konverter DC-DC yang mampu menyediakan tegangan keluaran yang lebih rendah dibandingkan tegangan masukan $\left(V_{o}<V_{\text {in }}\right)$ dengan mengatur duty cycle. Pada gambar 1 menunjukkan rangkaian konverter buck yang terdiri dari tegangan masukan $\left(V_{i n}\right)$, saklar, 
dioda, induktor $\mathrm{L}$, kapasitor $\mathrm{C}$, dan resistansi beban R [1-3].

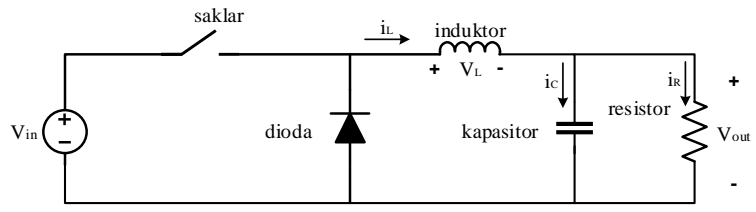

Gambar1. Rangkaian Konverter Buck.

Pada konverter buck terdapat dua kondisi analisis yaitu pada saat saklar dalam kondisi "ON". Pada gambar 2 menunjukkan rangkaian konverter buck saat kondisi saklar "ON", maka arus akan mengalir ke induktor dan beban.

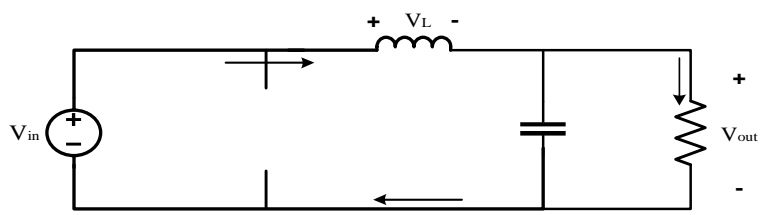

Gambar 2. Rangkaian Konverter Buck saat kondisi Saklar "ON"

Kondisi ini disebut periode pengisian arus induktor dan dioda dalam keadaan reverse bias. Maka dapat dicari rumus matematiknya sebagai berikut ini:

$V_{\text {in }}=V_{L}+V_{\text {out }}$

$V_{\text {in }}=L \frac{a_{i}}{a_{t}}+V_{\text {out }}$

$V_{\text {in }}=L \frac{\Delta_{i L}(\text { on) }}{\tau_{\text {on }}}+V_{\text {out }}$

$V_{\text {in }}=L \frac{\Delta_{i L}(\text { on })}{v T}+V_{\text {out }}$

$\Delta_{i L(\text { on })}=\frac{\left(V_{i n}-v_{\text {out }}\right) U T}{L}$

Selanjutnya adalah analisis pada kondisi saklar "OFF" seperti pada gambar 3, maka dioda akan forward bias karena adanya pengosongan dari induktor.

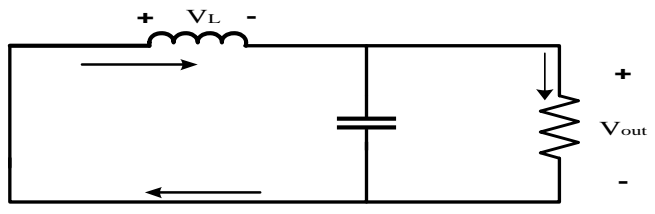

Gambar 3. Rangkaian Konverter Buck saat kondisi saklar"OFF"

Arus mengalir dari induktor ke beban dilanjutkan ke dioda dan kembali lagi ke induktor. Karena arus yang mengalir adalah arus pengosongan induktor saja dan induktor bersifat murni (tidak ada resistansi) maka arus akan membentuk kurva linier menurun. Oleh karena ini $V_{o}<V_{i n}$ dengan menggunakan konverter buck. Maka dari itu dapat dicari rumus matematiknya sebagai berikut ini:

$$
\begin{aligned}
& -V_{\text {out }}=V_{L} \\
& -V_{\text {out }}=L \frac{d_{i}}{a_{t}} \\
& -V_{\text {out }}=L \frac{\Delta_{\mathrm{Z}}(\text { off })}{\tau_{\text {off }}} \\
& -V_{\text {out }}=L \frac{\Delta_{\mathrm{L}}(\text { off } f)}{(1-D)]} \\
& \Delta_{i L \text { (off })}=-\frac{V_{\text {out }}(1-D)_{I}}{L}
\end{aligned}
$$

\subsection{Konverter Boost}

Konverter boost adalah salah satu DCDC yang mampu menghasilkan tegangan keluaran yang lebih tinggi dibandingkan tegangan masukannya $\left(V_{o}>V_{i n}\right)$. Rangkaian konverter boost yang terdapat pada gambar 4 terdiri dari beberapa komponen, antara lain tegangan sumber $\left(V_{i n}\right)$, saklar, dioda, induktor $\mathrm{L}$, kapasitor $\mathrm{C}$, dan resistansi beban $\mathrm{R}$ [1], [2],[3].

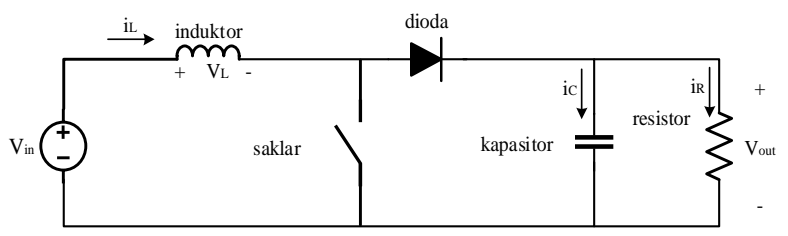

Gambar 4. RangkaianKonverter Boost. 
Pada converter jenis boost juga memiliki dua kondisi analisi yaitu pada saat saklar "ON" dan saat kondisi saklar "OFF". Pada gambar 5 menunjukkan rangkaian konverter boost dalam kondisi saklar "ON", maka induktor akan terhubung langsung dengan sumber atau $V_{\text {in }}$ dan akan mengalami proses pengisian (charging).

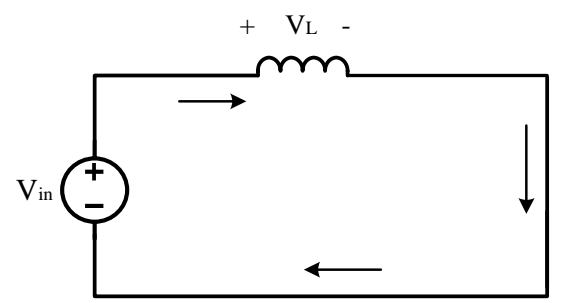

Gambar 5. Rangkaian KonverterBoost saat kondisi Saklar "ON"

Maka dari itu dapat dicari rumus matematiknya sebagai berikut ini:

$V_{\text {in }}=V_{L}$

$V_{\text {in }}=L \frac{d_{i}}{a_{t}}$

$V_{\text {in }}=L \frac{\Delta_{\text {I }}(\text { on })}{\tau_{0 n}}$

$V_{\text {in }}=L \frac{\Delta \text { iz }(\text { on })}{\Delta T}$

$\Delta_{i L}(o n)=\frac{V_{i n} \nu T}{L}$

Selanjutnya adalah analisis pada kondisi saklar "OFF" seperti pada gambar 6 . Tegangan masukan $\left(V_{i n}\right)$ akan terangkai seri dengan induktor dan resistor. Induktor yang semula dalam keadaan pengisian berubah menjadi pengosongan arus dan dalam kondisi ini induktor berfungsi sebagai sumber arus atau sumber tegangan $V_{L}$ dan resistor berfungsi sebagai beban yang di catu oleh dua sumber tegangan yaitu $V_{i n}$ dan $V_{L}$.

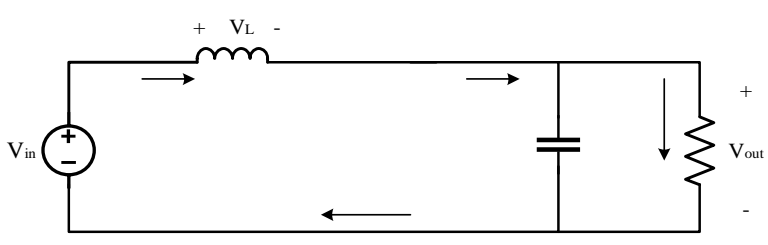

Gambar 6. Rangkaian Konverter Boost saat kondisi Saklar "OFF"

Maka dari itu dapat dicari rumus matematiknya sebagai berikut ini:

$V_{\text {in }}=V_{L}+V_{\text {out }}$

$V_{\text {in }}=L \frac{d_{i}}{a_{t}}+V_{\text {out }}$

$V_{\text {in }}=L \frac{\Delta_{\mathrm{Z}}(\text { off })}{\tau_{\text {off }}}+V_{\text {out }}$

$V_{\text {in }}=L \frac{\Delta_{\mathcal{Z}}(\text { off } f)}{(1-D) T}+V_{\text {out }}$

$\Delta_{i L(\text { off })}=\frac{\left(V_{\text {in }}-V_{\text {out }}\right)(1-D)_{I}}{L}$

\subsection{Konverter DC-DC Bidirectional}

Konverter DC-DC bidirectional beserta penyimpanan energi menjadi pilihan yang menjanjikan bagi banyak sistem yang berhubungan dengan daya, termasuk kendaraan hibrida, kendaraan dengan bahan bakar baterai, sistem energi terbarukan, dan sebagainya. Selain itu, dengan menggunakan sistem bidirectional tidak hanya mengurangi biaya dan meningkatkan efisiensi, tetapi juga meningkatkan performa pada sistem. Pada sistem energi terbarukan, multiple-input konverter DC-DC bidirectional digunakan untuk menggabungkan sumber energi yang berbeda. Rangkaian konverter DC-DC bidirectional ditunjukkan pada Gambar 7. Pada Gambar 8 menunjukkan aplikasi dari saklar yang akan digunakan pada konverter DC-DC bidirectional sehingga konverter akan dapat bekerja dalam dua mode, yaitu mode buck dan mode boost [3],[4],[7].

Untuk menerapkan aliran arus dua arah pada konverter DC-DC bidirectional, maka 
saklar pada konverter harus dapat mengalirkan arus pada kedua arah. Biasanya konverter tersebut diaplikasikan dengan menggunakan saklar daya unidirectional semiconductor, seperti MOSFET atau IGBT. Oleh karena itu, dengan penambahan dioda yang terpasang seri dengan saklar akan dapat digunakan untuk mengalirkan arus dua arah [8],[9].

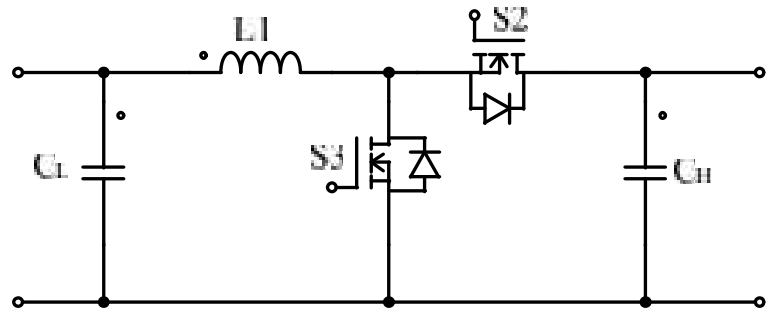

Gambar. 7. Rangkaian Konverter DC-DC Bidirectional.
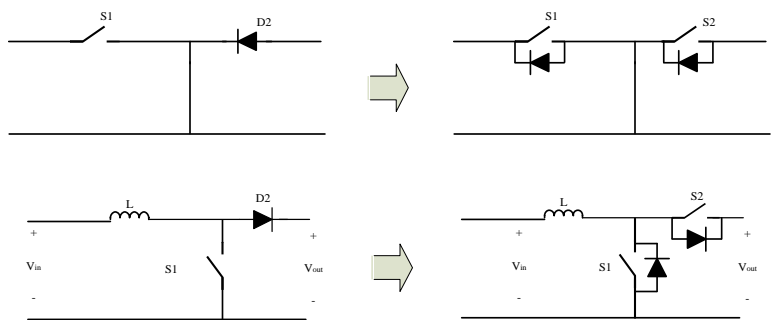

Gambar. 8. Pemodelan Saklar pada Konverter DC-DC Bidirectional.

\subsection{Desain Sistem}

Penelitian ini dilakukan di bidang power electronic khususnya proses konversi energi listrik untuk mengatur energi listrik dalam proses kebutuhan penyediaan untuk beban dan energi storage. Untuk desain penelitian yang dilakukan ditunjukkan pada gambar 9.

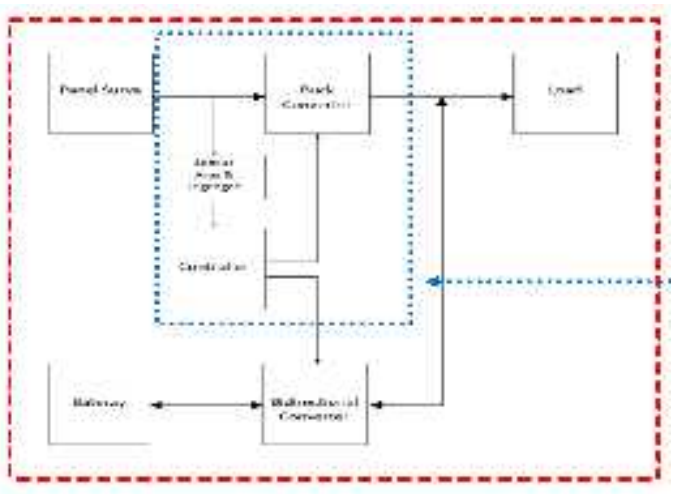

Gambar 9. Blok Diagram Sistem
Seperti yang ditunjukan pada blok diagram diatas, implementasi DC-DC bidirectional converter pada system sehingga dapat meminimalkan jumlah converter yang digunakan. DC-DC Bidirectional konverter berfungsi sebagai mode buck dan mode boost. DC-DC Bidirectional converter akan berfungsi sebagai mode buck pada saat ada energi listrik lebih yang dihasilkan dari panel surya.

Pada saat panel surya menghasilkan daya yang maksimal sehingga dapat memenuhi daya beban secara langsung dan sisanya dapat digunakan untuk proses pengisian baterai. Bidirectional converter akan berfungsi sebagai mode boost pada saat daya yang dihasilkan dari panel surya tidak mampu memenuhi untuk beban. Sehingga baterai akan memberikan sumber tegangan / daya pada beban. Untuk aliran daya dapat ditunjukkan seperti pada gambar 10. DC-DC Bidirectional converter ditunjukkan seperti pada gambar 11.

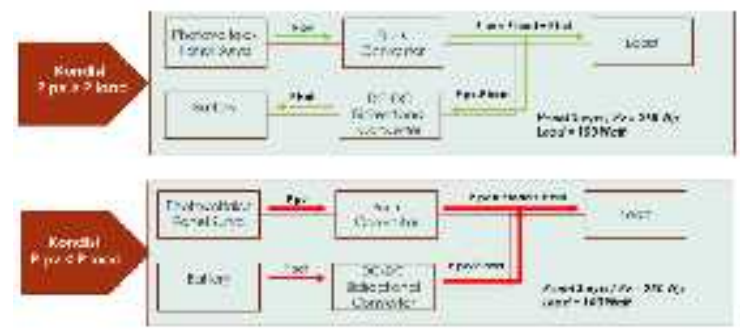

Gambar 10. Aliran Daya Pada Implementasi DC-DC Bidirectional.

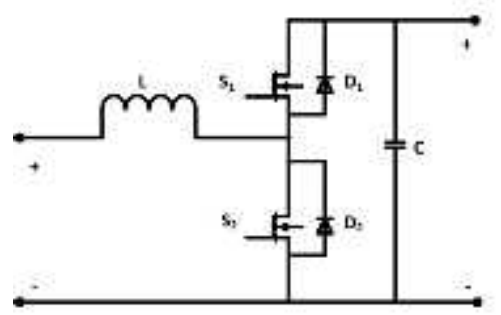

Gambar 11. DC-DC Bidirectional Converter

Pengaturan dalam pengoperasian bidirectional converter dilakukan dengan menggunakan mikrokontroller Arm STM32. Mikrokontroller digunakan untuk mengatur proses switching dari converter. Proses 
switching converter dilakukan dengan pengaturan PWM (Pulse Width Modulation) dengan frekuensi tertentu sehingga mendapatkan hasil tegangan yang maksimal.

\section{Hasil Penelitian}

Berdasarkan desain sistem yang telah diusulkan maka dilakukan proses pengujian untuk melihat kehandalan dari sistem bidirectional pada kondisi kerja charging dan discharging. Desain simulasi untuk sistem ini menggunakan program PSIM, gambar rangkaian simulasi ditunjukkan seperti pada gambar 12.

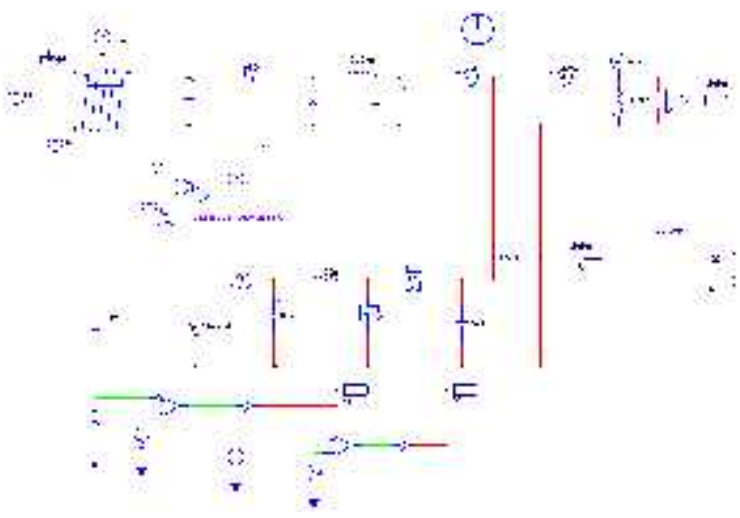

Gambar 12. Rangkaian Simulasi Sistem DC - DC Bidiretctional

Terdapat dua kondisi pengujian yang telah dilakukan, kondisi pertama adalah jika daya pada panel surya lebih besar daripada beban yang digunakan. Maka pada kondisi ini panel surya mensuplai kebutuhan daya dan melakukan proses charging. Detail hasil pengujian kondisi ini ditampilkan pada gambar 13 dan tabel 1.

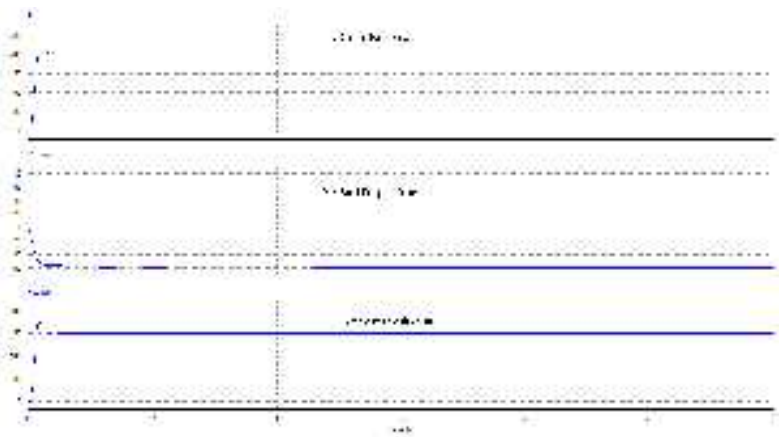

Gambar 13. Hasil pengujian pada kondisi daya panel surya lebih besar dari beban

Tabel 1. Detail hasil pengujian pada kondisi daya panel surya lebih dari beban

\begin{tabular}{clc}
\hline No. & \multicolumn{1}{c}{ Keterangan } & $\begin{array}{c}\text { Daya } \\
\text { (W) }\end{array}$ \\
\hline 1 & Daya yang dihasilkan panel surya & 207.23 \\
2 & Daya yang dibutuhkan beban & 149.04 \\
3 & Sisa daya sebagai charging batrai & 58.28 \\
\hline
\end{tabular}

Dari hasil tersebut dapat diketahui bahwa pada kondisi ini sistem melakukan charging sehigga converter berfungsi sebagai mode buck dimana converter menurunkan tegangan dari panel surya sebagai suplai baterai pada range tegangan 13.5 Volt. Setelah dilakukan proses charging dapat dilihat tegangan baterai menjadi lebih dari 12 volt dan terjadi kenaikan pada SOC baterai. Detail proses charging ditampilkan pada gambar 14 .

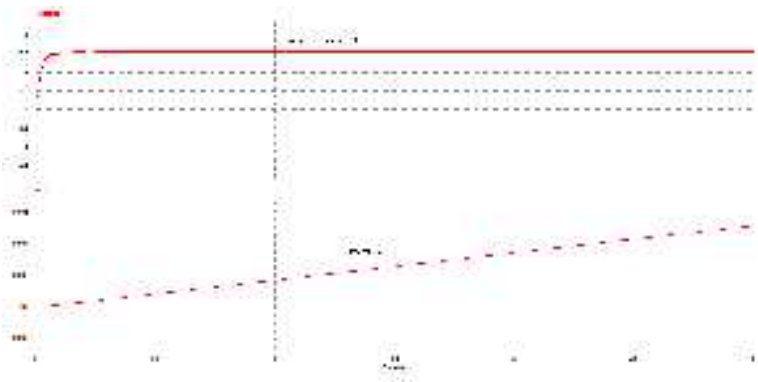

Gambar 14. Hasil pengujian proses charging baterai

Kondisi selanjutnya adalah apabila daya yang dibutukan oleh beban lebih besar dari pada yang dihasilkan oleh panel surya, maka pada kondisi ini sistem melakukan load sharing atau discharging untuk mencukupi kebutuhan beban. Detail pengujian pada 
kondisi ini ditampilkan pada gambar 15 dan tabel

2.

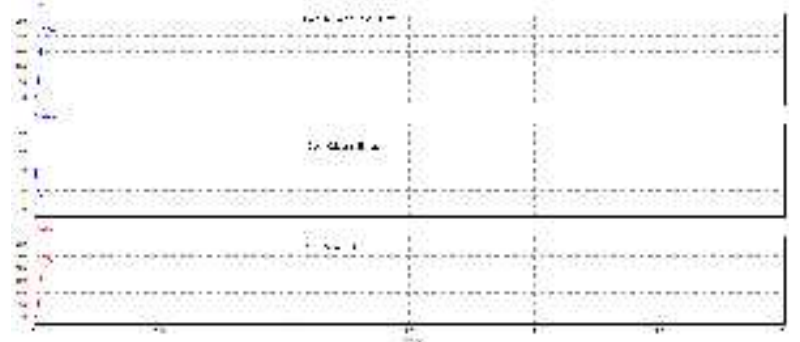

Gambar 15. Hasil pengujian pada kondisi daya beban lebih besar dari panel surya

Tabel 2. Detail hasil pengujian pada kondisi daya beban lebih besar dari panel surya

\begin{tabular}{ccc}
\hline No. & Keterangan & $\begin{array}{c}\text { Daya } \\
\text { (W) }\end{array}$ \\
\hline 1 & Daya yang dihasilkan panel surya & 219.86 \\
2 & Daya yang dibutuhkan beban & 232.53 \\
3 & Daya yang disuplai baterai & 12.97 \\
\hline
\end{tabular}

Dari hasil tersebut dapat diketahui bahwa pada kondisi ini sistem melakukan discharging (Load swharing) sehigga converter berfungsi sebagai mode boost dimana converter menaikan tegangan dari baterai sebsar 12 volt untuk mencapai tegangan pada beban yaitu 24 volt. Dimana dalam hal ini dapat dilihat hasil penaikan tegangan dan proses penurunan SOC baterai yang ditampilkan pada gambar 16 dan gambar17.
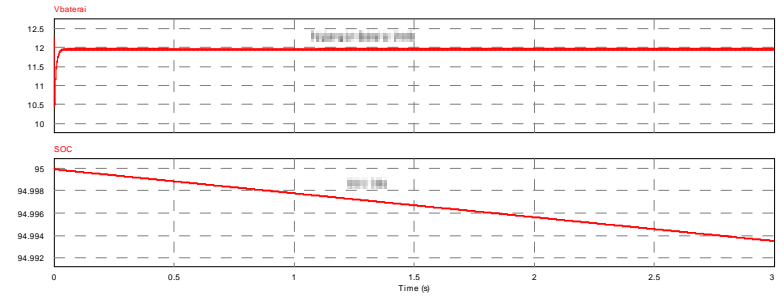

Gambar 16. Hasil pengujian tegangan dan SOC baterai pada kondisi proses discharging (Load Sharing)
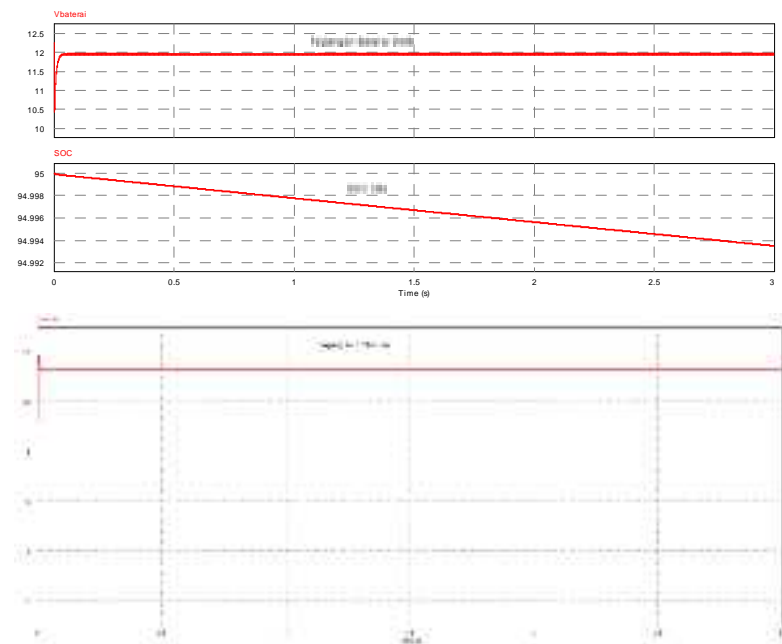

Gambar 16. Hasil pengujian tegangan beban pada kondisi proses discharging (Load Sharing)

\section{Kesimpulan}

Berdasarkan hasil simulasi dapat diketahui bahwa sistem converter bidirectional yang diusulkan dapat bekerja dengan baik, dimana ketika daya pada panel surya lebih besar dari pada beban maka converter secara auto berubah menjadi mode buck (penurun tegangan) untuk melakukan proses charging baterai dan mensuplai beban. Kemudian jika daya pada panel surya lebih kecil dari beban maka converter langsung berubah menjadi mode boost (penaik tegangan) baterai untuk mencapai tegangan beban dalam hal ini disebut dengan kondisi load sharing (Discharging).

\section{Saran}

Diperlukan penambahan sistem kontrol untuk menjaga agar tegangan keluaran pada sistem bidirectonal tetap konstan sesuai dengan tegangan kerja atau seting point yang ditentukan pada kedua mode buck dan boost. Selain itu untuk memaksimalkan daya yang dihasilkan dari PLTS maka diperlukan Metode Power Point Tracking. Sehingga dengan adaya $D C-D C$ Bidirectional Converter yang effisien dan MPPT bisa meningkatkan daya listrik yang dihasilkan untuk memenuhi kebutuhan daya listrik beban. 


\section{Daftar Pustaka}

[1] Deepak Ravi1, Bandi Mallikarjuna Reddy, Shimi S.L., Paulson Samuel, "Bidirectional dc to dc Converters: An Overview of Various Topologies, Switching Schemes and Control Techniques", International Journal of Engineering \& Technology, 7 (4.5) (2018) pp.360-365, 2018.

[2] M.Shahriman M. Sarif, Tan Xin Pei, A.Z. Annuar, "Modeling, Design and Control of Bidirectional DC-DC Converter Using StateSpace Average Model”, 2018 IEEE Symposium on Computer Applications \& Industrial Electronics (ISCAIE), 2018.

[3] Indhana Sudiharto, Indra Ferdiansyah, Diah Septi Yanaratri Mochamad Abdul Mughis, "Design and Implementation of Partial MType Zero Voltage Resonant Circuit Interleaved Bidirectional DC-DC Converter (Energy Storage and Load Sharing)," in 2018 International Electronics Symposium on Engineering Technology and Applications (IES-ETA), Bali, Indonesia, 2018, pp. 123-128.

[4] Lee. Kun-Ying and Liao. Kuo-Fu Hsieh. Yao-Ching, "An Interleaved Bidirectional DC-DC Converter with Zero-VoltageSwitching," in IEEE 10th International Conference on Power Electronics and Drive Systems (PEDS), Kitakyushu, Japan, 2013.
[5] Kuei-Hsiang. Tseng, Ming-Chang. Huang , Chun-Hao Chao, "Design and implementation of a Bidirectional DC-DC Converter for Stand-Alone Photovoltaic Systems," Internatonal Journal of Computer, Consumer and Control (IJ3C), vol. 2, no. 3, 2013.

[6] Zhaojun Tao, Lei Li, "Control Loop Design and Bidirectional Control Strategy of a Bidirectional DC/DC Converter", IECON 2017 - 43rd Annual Conference of the IEEE Industrial Electronics Society, 2017.

[7] Ching Ming Lai, Yuan-Chih Lin, dan Dasheng Lee, "Study and Implementation of a Two-Phase Interleaved Bidirectional DC/DC Converter for Vehicle and DCMicrogrid Systems", Energies (19961073), Sep2015, Vol. 8 Issue 9, p9969-9991. 23p, 2015.

[8] Babu P Emmanuel, S Ashok, S Kumaravel Krishnan K Gokul, "Design and control of non-isolated bidirectional DC-DC converter for energy storage application," in 2017 2nd IEEE International Conference on Recent Trends in Electronics, Information \& Communication Technology (RTEICT), Bangalore, India, 2017, pp. 289-293.

[9] Issa Batarseh, Power Electronic Circuits. USA: John Wiley \& Sons, Inc, 2004. 